\title{
Awake bronchoscopic intubation through an air-Q® with the application of BIPAP
}

\author{
David T. Wong, MD · Jane Wang, MD • \\ Lashmi Venkatraghavan, MD
}

Received: 1 April 2012/ Accepted: 24 May 2012/Published online: 22 June 2012

(c) Canadian Anesthesiologists' Society 2012

\section{To the Editor,}

Awake tracheal intubation is recommended for patients with a known or suspected difficult airway. A supraglottic airway device has been used as a conduit for awake intubation with a flexible bronchoscope. ${ }^{1}$ We describe an awake bronchoscope-guided tracheal intubation through an air-Q ${ }^{\circledR}$ intubating laryngeal airway (air-Q ${ }^{\circledR}$, Mercury Medical, Clearwater, FL, USA) with continuous application of bilevel positive airway pressure (BIPAP) in a patient with a difficult airway and respiratory failure. Written consent was obtained from the patient for the publication of this article.

A 46-yr-old, 146-kg man with severe obstructive sleep apnea and obesity hypoventilation syndrome was admitted to the intensive care unit (ICU) for acute respiratory failure. Six months prior, an emergency cricothyroidotomy was performed after a prolonged awake fibreoptic tracheal intubation failed due to rapid oxygen desaturation and repeated closure of false vocal cords during intubation. In this case, a decision was made to perform an urgent tracheostomy as previous tracheal intubation attempts had failed. An awake tracheostomy was likely difficult due to our patient's anatomy, intolerance of supine positioning, and respiratory failure. Therefore, we planned to perform an awake tracheal intubation followed by induction of anesthesia and tracheostomy in the operating room (OR).

The patient was transferred from the ICU to the OR on BIPAP $\left(25 / 12 \mathrm{~cm} \mathrm{H}_{2} \mathrm{O}\right)$; his oxygen saturation was $94 \%$ with an inspired oxygen fraction $\left(\mathrm{F}_{1} \mathrm{O}_{2}\right)$ of 1.0, and the surgeons were prepared with their tracheostomy

D. T. Wong, MD $(\bowtie) \cdot J$. Wang, MD $~$ L. Venkatraghavan, MD Toronto Western Hospital, University of Toronto, Toronto, ON, Canada

e-mail: david.wong@uhn.on.ca equipment. Standard monitors were applied, and following intravenous sedation, $4 \%$ topical lidocaine was atomized nasally and orally. During topicalization, BIPAP was reapplied repeatedly because of oxygen desaturation. The oral insertion of a size 4.5 single-use air-Q in the sitting position was well tolerated, and BIPAP was applied to the air-Q (Figure, top), followed by the insertion of a $6.5-\mathrm{mm}$ endotracheal tube (ETT) via the air-Q to $14 \mathrm{~cm}$. The ETT cuff was inflated, and BIPAP was connected to the ETT through a flexible connector with a bronchoscope port (Figure, bottom). A bronchoscope (outside diameter 5.2 $\mathrm{mm}$ ) was advanced through the flexible connector past the well-visualized glottis to the carina. The ETT cuff was deflated and advanced over the bronchoscope into the trachea. After re-inflation of the ETT cuff and confirmation of tracheal positioning of the ETT with the bronchoscope, a general anesthetic was administered, and the ETT/air-Q unit was taped to the patient's face. An oxygen saturation $>97 \%$ was maintained during the intubation process. A tracheostomy was performed uneventfully.

Bilevel positive airway pressure is used frequently in patients with respiratory failure or obstructive sleep apnea. ${ }^{2}$ In this case, it appears that continuous BIPAP through the air-Q was better tolerated by our patient than intermittent BIPAP via a tightly strapped facemask, and oxygenation was improved during tracheal intubation. The role of BIPAP is to improve functional residual capacity, reduce atelectasis, and prevent hypoxemia. The splinting effect of positive ventilatory pressures also prevents the collapse of upper airway structures during spontaneous breathing. By stenting open the upper airway, BIPAP may have improved our visualization of the vocal cords. Alternative techniques of awake intubation have been described with devices such as videolaryngoscopes, rigid fibreoptic laryngoscopes, and fibreoptic/lighted stylets; however, none of these 

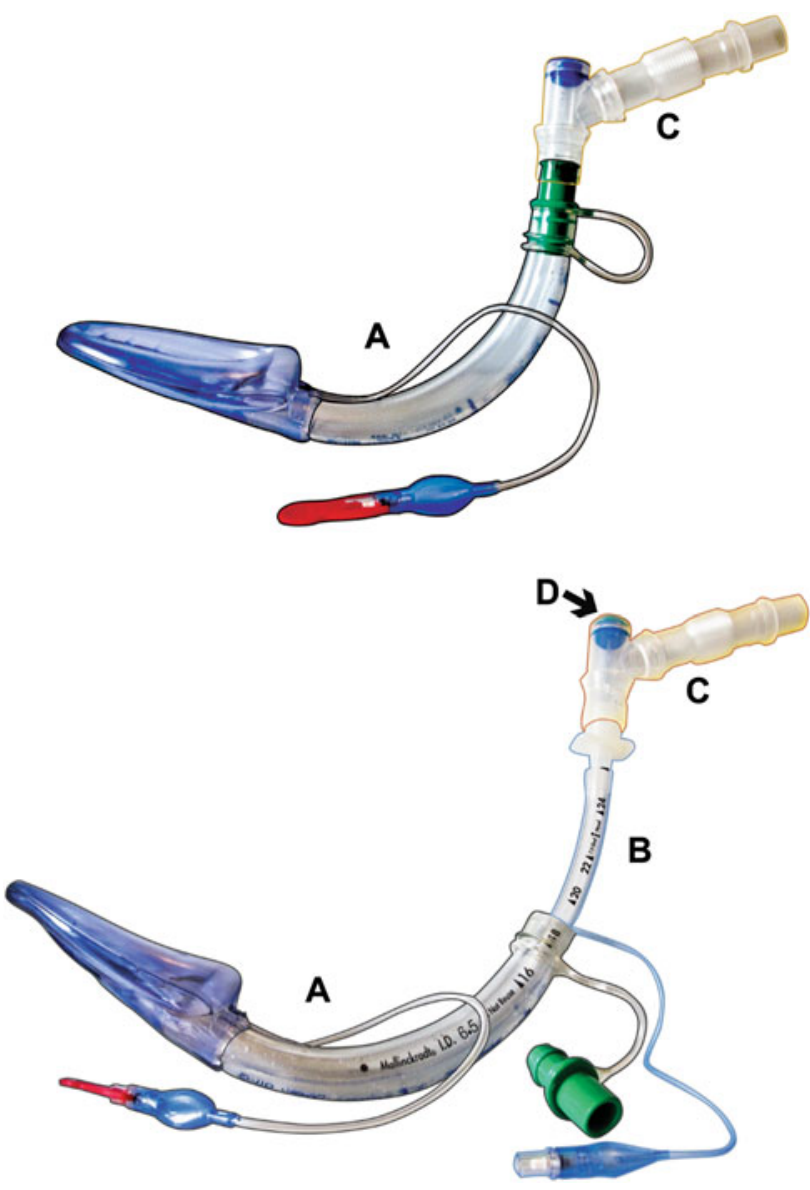

Figure (Top) $\mathrm{A}=$ air- $\mathrm{Q}{ }^{\circledR} ; \mathrm{C}=$ flexible connector. After insertion of the air- $\mathrm{Q}{ }^{\circledR}$, bilevel positive airway pressure (BIPAP) is connected to it through a flexible connector. (Bottom) $\mathrm{A}=$ air- $\mathrm{Q}{ }^{\circledR} ; \mathrm{B}=$ tracheal tube; $\mathrm{C}=$ flexible connector; $\mathrm{D}=$ bronchoscope port. $\mathrm{A}$ tracheal tube is inserted into the air-Q ${ }^{\circledR}$ to $14 \mathrm{~cm}$, and the tracheal tube is connected via a flexible connector with a bronchoscope port to the BIPAP equipment

techniques permit continuation of BIPAP during the intubating attempt.
Awake insertion of a supraglottic airway followed by fibreoptic-guided tracheal intubation has been described in patients with morbid obesity and a difficult airway ${ }^{3,4}$; however, in both cases, a general anesthetic was administered prior to ETT insertion and BIPAP was not used. Our technique, which allows the maintenance of BIPAP through the ETT and air-Q during intubation, can be employed using any supraglottic airway that allows the passage of a large ETT (e.g., LMA Fastrach ${ }^{\mathrm{TM}}$, i-gel®, Ambu ${ }^{\circledR}$ AuraOnce $\left.{ }^{\mathrm{TM}}\right)$. We chose the air-Q because it was immediately available.

In summary, we describe the novel application of nearly continuous BIPAP during an awake bronchoscope-guided intubation through the air-Q. This technique may be useful in performing awake tracheal intubation in patients with difficult airways who have respiratory failure or collapsible upper airway structures.

Funding sources Study supported, in part, by the Department of Anesthesia, Toronto Western Hospital, University of Toronto.

Competing interests None declared.

\section{References}

1. Wong DT, Zilberman $P$. Awake intubation through an intubating laryngeal airway (ILA) in a patient with Still's disease. Can J Anesth 2010; 57: 286-7.

2. Poponick JM, Renston JP, Bennett RP, Emerman CL. Use of a ventilatory support system (BiPAP) for acute respiratory failure in the emergency department. Chest 1999; 116: 166-71.

3. Doyle DJ, Zura A, Ramachandran M, et al. Airway management in a 980-lb patient: use of the Aintree intubation catheter. J Clin Anesth 2007; 19: 367-9.

4. Wender R, Goldman AJ. Awake insertion of the fibreoptic intubating LMA CTrach in three morbidly obese patients with potentially difficult airways. Anaesthesia 2007; 62: 948-51. 